\title{
Shanghai Gong Shang Magazine and Shanghai Modern Textile Industry
}

\author{
Huaming Zhang ${ }^{1} \&$ Dawei Liao ${ }^{1}$ \\ ${ }^{1}$ College of Humanities, Donghua University, Songjiang, Shanghai, China \\ Correspondence: Dawei Liao, College of Humanities, Donghua University, Songjiang, Shanghai, 201620, China. \\ E-mail: liaodawei1961@163.com
}

Received: August 30, 2020

doi:10.5539/ass.v16n10p65
Accepted: September 7, 2020

Online Published: September 24, 2020

URL: https://doi.org/10.5539/ass.v16n10p65

\begin{abstract}
Shanghai Gong Shang is an official journal of Shanghai Federation of industry and commerce. During the period from 1949 to 1951, there were a lot of information about textile industry in Shanghai Gong Shang. The role of Shanghai Gong Shang is not only to help the government to publicize industrial and commercial policies, but also to help the government understand the ideological trends of people in the industrial and commercial circles at that time, and to answer the practical problems of production in the industrial and commercial circles. When major events occur and important policies are implemented, there are a large number of articles on the journals to introduce and interpret the events and policies. Generally speaking, Shanghai Gong Shang is an important information to understand the situation of industry, commerce and textile industry at that time.
\end{abstract}

Keywords: Shanghai Gong Shang, Shanghai Modern Textile Industry, Textile Journals

Shanghai Gong Shang is an official journal of Shanghai Federation of industry and commerce. Its title was inscribed by Yi Chen, mayor of Shanghai at that time. Shanghai Gong Shang started publication on November 5, 1949, and stopped publication in June 1962, with a total of 353 issues. At first, it was affiliated to the Preparatory Committee of Shanghai Federation of industry and commerce. As an important magazine for the CPC to publicize its own industrial and commercial policies in Shanghai, it published a large number of policy oriented articles. On the one hand, it reflected the industrial and commercial policies of the government at that time, and also showed the government's attitude towards the bourgeoisie in Shanghai to a certain extent.

\section{General Situation of Shanghai Gong Shang Publishing Houses}

At the beginning of its establishment, Shanghai Gong Shang was published on the 1st, 11th and 21st days of each month, with 16 volumes and 30000-40000 words per issue. Shanghai Gong Shang was issued by Pihua Sheng, edited by Nianzhi Pan and Tiemin Li, Yuchen Fu and Qingming Qiu. The number of subscribers in the first month was 1129. By March 23, 1950, the number of subscribers increased to 1562. In the early days of the founding of the People's Republic of China, the circulation of Shanghai Gong Shang was relatively low, and most of them were businessmen in Shanghai. At first, it was managed and issued by the Preparatory Committee of Shanghai Federation of industry and commerce. Until July 1952, Shanghai Gong Shang was entrusted to be issued by the Municipal Post and Telecommunications Bureau. At that time, the circulation was 3000 copies.

In August 1952, Pihua Sheng was still in charge of Shanghai Gong Shang. The chief editors were Keang Zhao and Ziheng Liang, and the editor was Xueyun Xu. At this time, the editorial department of Shanghai Gong Shang put forward a new editorial policy, that is, "combining with the actual requirements of production and learning of the industrial and commercial circles, helping and enlightening the industrial and commercial circles from specific problems, so as to make the journal play an ideological leading role and carry out the work from the masses to the masses." On the 15th of the same month, periodical appearing once every ten days was changed into a weekly, which was published every Friday. The 16th edition was changed into the 25th edition. Since then, the size of Shanghai Gong Shang magazine has been constantly adjusted, and the publishing cycle industry has been constantly changing. In January 1953, Shanghai Gong Shang was changed from 25 to 32. From the third quarter of 1954, it was changed into a semimonthly magazine, and it was changed back to the original 16 format edition. It is published on the 5th and 20th of each month, and the content is further expanded, with about 50000 words per issue. The price is 1500 yuan (old RMB) per month. The circulation was 58 in 1954 and 6600 in 1955. In January 1956, the journal carried out the policy of facing the masses, popularized, popularized, changed long 
monographs and focused on short and vivid articles. Cover changed to color, enrich the picture, and enlarge the font. After that, the circulation increased rapidly, reaching 12000 copies in 1956 and more than 18000 copies in 1957-1958.

In March 1959, the joint meeting of the Shanghai Federation of Industry and Commerce and the vice chairman of the Shanghai Municipal People's Congress of civil construction decided to change the "Shanghai Gong Shang" into an official journal. The "two sessions of Shanghai Industrial and commercial publishing house" and the "two sessions of Shanghai Municipal Industrial and commercial publishing committee" were clearly defined, and the "two sessions of Shanghai Industrial and commercial publishing house" were jointly organized and approved. In 1960, after being submitted to the Shanghai Publishing Bureau, the semimonthly magazine was changed into a monthly one, which was published on the 5th day of each month. The price of each issue was 0.10 yuan. From August to December of the same year, it was suspended for rectification. On December 3, it was approved by the municipal Publishing Bureau and issued the Shanghai Journal registration certificate. In January 1961, Shanghai Gong Shang resumed publication. The publication highlights positive publicity as the main principle and mainly propagandizes the ideological transformation of the industrial and commercial circles. In June 1962, due to the shortage of raw materials and the shortage of paper in China, the newspapers and periodicals of the industrial and commercial circles in various regions were suspended. On June 7, the joint meeting of the chairmen and vice chairmen of the Municipal People's Congress and the Municipal People's Congress decided to suspend the publication of Shanghai Gong Shang.

\section{The Image of Shanghai Textile Industry in Shanghai Gong Shang}

During the period from 1949 to 1951, there were a lot of introductions about textile industry in Shanghai Gong Shang. The image of textile industry in Shanghai Gong Shang is also from the beginning "facing great difficulties" to the later "typical representative" participating in national construction. The image of textile industry is gradually changing. It is a representative industry established by Shanghai Gong Shang to actively participate in the construction.

In 1950, there were still many problems in the supply of raw materials, the circulation of funds and the sales of products in the textile industry. Shanghai Gong Shang has investigated many enterprises in the textile industry, analyzed the difficulties they faced, and pointed out that "now the authorities are working out the industrial construction plan for 1950. 1950 will be a difficult last year. "The magazine first took the silk weaving industry as an example, saying that "Shanghai's silk weaving industry will also develop with the change of the new situation." The magazine of handmade cotton textile industry at this stage also appeared as a "new democratic economic policy fighter under overcoming difficulties". All these show an attitude of overcoming difficulties in difficulties and making efforts to carry out production. As the processing industry of textile industry, the printing and dyeing industry is also investigated by Shanghai Gong Shang. It is pointed out that the printing and dyeing industry is also facing great difficulties, which are not caused in a short period of time and cannot be solved in a short time. It is necessary to stabilize the market and then solve the capital problem of the printing and dyeing industry. It was also because of the great difficulties faced by the dyeing and weaving industry in 1949-1950 that the dyeing and weaving industry was not very active at the beginning of the debt buying movement, and there was some resistance. However, through the joint efforts of all parties, the dyeing and weaving industry has not only completed the initial goal of purchasing bonds, but also formulated the target and plan for further sales of government bonds. Under the call of the government's "anti-bombing", the textile industry also cooperated with the government as much as possible to insist on production, and signed a new labor contract for production during the anti-bombing period according to the requirements of the government. Although ZhenXin knitting factory is very close to the waterworks in the heavily hit area, it is still under the guidance of the government to "move the machines back to the original factory and continue to start work" and resume production rapidly. Generally speaking, the whole textile industry is facing great difficulties at this stage, but in the difficulties, the whole industry tries to overcome the difficulties for development, and at the same time, it also has a positive response to the government's policies and movements. At this stage, the image of the textile industry has always been a microcosm of Shanghai's industrial and commercial circles, and it has been developing in difficulties. After November 1950, Shanghai Gong Shang published a lot of policies and management measures for the textile industry, involving many aspects of the textile industry. In the magazine, the textile industry also has a positive response to these policies, and the whole Shanghai textile industry has become a typical example of the gradual reform of the industrial and commercial circles in this period. It is also because of the improvement of the overall economic situation and the production situation of the textile industry at this stage, the government intends to restrict and manage the textile industry more.

On October 30, 1950, Shanghai cotton yarn began centralized trading and management. This is a management 
regulation implemented by the Shanghai municipal government at that time in order to rationalize the supply and demand of cotton yarn and make the production more planned. Shanghai Gong Shang also published articles such as "implementing the management spirit of centralized trading of cotton yarn" and "the basic spirit of new measures for managing cotton yarn Market", etc, to publicize these management policies which tend to be planned in the market. At this time, the textile industry has been gradually incorporated into the whole planned economy system. In this stage, dyeing and weaving mills and yarn mills, as typical examples of overcoming difficulties and realizing enterprise transformation, have been intensively publicized in magazines. Taking a single enterprise as an example, Shanghai Gong Shang sorted out the production situation from the early liberation to the end of 1950, summarized the transformation experience, and carried out a lot of publicity as a typical example of industrial and commercial transformation.

At the end of 1950, the transformation of private enterprises began. In the early days of the founding of the People's Republic of China, the people's government should encourage the private economic undertakings that are beneficial to the national economy and the people's livelihood, and help them develop. Therefore, private enterprises played an important role in the new democratic economy at that time. "Transforming private enterprises to meet the needs of the national economy and the people's livelihood is one of the important conditions for restoring, maintaining and developing the people's economy." "At present, private enterprises in Shanghai still account for a considerable proportion in various social and economic components. Therefore, in accordance with the spirit of the common program and under the leadership of the government and the state-owned economy, it is an important task for the recovery and development of the Shanghai People's economy to carry out the transformation of the private enterprises and improve the production of the private enterprises." Therefore, the main task of Shanghai's industrial and commercial circles at this stage is to transform the private enterprises. The most important basis for the transformation is the common program, which makes the private enterprises subject to the leadership of the national economy. This is an important stage of transforming capitalism into state capitalism in the process of socialist transformation. In this stage, textile industry, as a typical private enterprise, has a large number of reports in Shanghai Gong Shang. In addition to policy publicity meetings and seminars, private textile mills are often cited as examples. In the enterprise transformation album of Shanghai Gong Shang, almost all of them take private enterprises in the textile industry as examples. Among the six articles on enterprise transformation published in the album, five are related to the textile industry, including the experience of Gongsheng dyeing and weaving mill in overcoming difficulties in enterprise transformation, Xinyu cotton mill's experience in overcoming difficulties in enterprise transformation, Zhaofeng cotton mill's experience in overcoming difficulties in enterprise transformation, and Dalong manufacturing machinery factory's experience in overcoming difficulties in enterprise transformation, experience of Dacheng silk factory in overcoming difficulties and engaging in enterprise transformation. These five articles are related to printing and dyeing, spinning, weaving, textile machinery manufacturing and other textile industry components.

This paper reviews the process of the transformation of these private enterprises in the textile industry, and reviews the difficulties and the causes of the difficulties. All the enterprises mentioned the difficulties in raw materials caused by Haikou blockade and the energy shortage after the 26th bombing. The difficulties in working capital are also common, but the causes are different. Gongsheng dyeing and weaving factory was lack of funds. At the beginning of liberation, it was difficult to exchange materials between urban and rural areas, which made the circulation of funds longer, resulting in more shortage of funds. However, most of the other mills were short of funds due to the rising cost of raw materials and the poor sales of the products produced in the early days of the People's Republic of China. Different private enterprises also face different difficulties in other aspects. For example, Gongsheng dyeing and weaving factory faces difficulties such as high interest rate and over staffing.

In the process of overcoming these difficulties, all enterprises have been helped by the Municipal Labor Bureau, the state-owned flower gauze company and the Municipal Federation of industry and commerce. It is important that the key link of the transformation of these textile related enterprises is the transformation of labor relations. The reasons for the improvement of the production and operation of enterprises are the transformation of labor relations and the conclusion of new labor and capital conventions. In Gongsheng dyeing and weaving factory, the trade union and the Youth League in the factory are improving the grass-roots groups and starting to establish new labor relations. All matters in the factory are discussed democratically by the various groups, and the decisions are concentrated. "With regard to the issue of production improvement, the trade union shall propose to adopt the reward system." In summing up the experience of Gongsheng's labor and capital transformation, Shanghai Gong Shang commented that "it is the best way for Gongsheng's labor and capital to take the initiative to transform and save by production". "The reason why Gongsheng's production can be improved is because of 
the objective and favorable conditions for the government to continue to give help many times, and the labor and capital can solve problems facing production." Similarly, in introducing the experience of Xinyu cotton mill in overcoming difficulties, it is also mentioned that "the unity of labor and capital relations is also an important reason for the company to overcome difficulties; since May, after the establishment of the labor and capital consultation meeting, the two sides have made great efforts to simplify and save in order to reduce costs, which has achieved remarkable results." Dalong manufacturing machinery factory and Dacheng silk factory also signed a new labor agreement under the coordination of all parties. After the signing of the new agreement, the contradiction between labor and capital has been alleviated, and both sides have made concessions in terms of the number of people returning to work. The enthusiasm of the workers has been greatly improved, and they have cooperated with the management to increase production and save money. Dacheng silk factory's experience in regulating the return to work of both employers and employees has also been publicized as a typical example. Dacheng silk factory management close to the labor side, sincerely accept the labor's opinions and gradually implement the relevant opinions, which has been recognized by the labor side. The labor side also "with the spirit of being the master, actively strive for the management, economize on food and clothing, overcome difficulties, and strengthen the management's confidence in maintaining production." According to Shanghai Gong Shang, Dacheng silk factory has achieved such good results in the reform of labor relations because of two basic conditions: the first is that the labor union is well organized and can go deep into the masses and lead the mass work. The second is that the management should be close to the government and follow the mass line. In short, in this stage of "Shanghai Gong Shang" publicity, the textile industry has become a model of private enterprise reform.

\section{Conclusion}

Through these publicity, we can see that the image of private textile enterprise owners and even the whole Shanghai industrial and commercial capitalists appeared in the publicity of "Shanghai Gong Shang" actively cooperating with the national economic development. Shanghai Gong Shang constantly put forward their own shortcomings, and carried out transformation and development according to the requirements of the government. In these three years, the textile industry has gradually become a model of private enterprise transformation. However, from another point of view, the owners of private enterprises have gradually changed from the leader of factory production management to the participants of enterprise production. The leading support of the government and the selfless dedication of the working class have become the main reasons why enterprises can continue to develop. What industry and commerce need to do is to actively cooperate. Under the condition that raw materials and markets are included in the government's plan, the businessmen in charge of running enterprises seem to have little to do. As in reviewing the private cotton textile industry in Shanghai in 1950, Shanghai Gong Shang summed up four points when talking about the reasons for the improvement of the cotton textile industry. To sum up, it is due to the leadership of the people's government, the efforts of the working class, the harvest of cotton and grain is the dedication of farmers, and finally, the cooperation between the cotton textile trade association and the government, which makes some enterprises understand the policies and carry out self-transformation. From the leading role of their own enterprises, business people have become an integral part of government policies.

\section{References}

Culture and History Office of all-China Federation of industry and Commerce. (1993). Memorabilia of all-China Federation of industry and Commerce. China Federation of industry and Commerce Press.

Jin, Z. H. (2006). The choice between the state and the private: the cotton policy of the national government after the war and the establishment of China Textile Construction Corporation. The Journal of Chinese Social and Economic History, (1).

Office of Shanghai establishment committee. (1988). Evolution of Shanghai's Party and Government Organizations 1949-1986. Shanghai Ren Min Chu Ban She.

Shanghai Gong Shang (1949-1951).

Zhang, Y. P. (2001). Records of Shanghai Industrial and Commercial Association. Shanghai Academy of Social Sciences Press.

\section{Copyrights}

Copyright for this article is retained by the author(s), with first publication rights granted to the journal.

This is an open-access article distributed under the terms and conditions of the Creative Commons Attribution license (http://creativecommons.org/licenses/by/4.0/). 